\title{
Drawing on nature: a vision of an urban residential street adapted for biodiversity in architectural drawings
}

Siân Moxon* ${ }^{*}$

\begin{abstract}
Cities are becoming more built up and less hospitable to wildlife, which is in alarming global decline. Consequently, cities are becoming worse for their human inhabitants, who benefit from contact with nature, and losing out on the vital ecosystem services that urban greenery provides. This is a particular issue in residential streets, as domestic gardens offer significant potential for greenspace and wildlife habitat, but their value is misunderstood and their management is largely unregulated. Visual communication techniques are effective at engaging residents in city planning and could therefore offer a solution by inspiring community action to rewild urban streets. The article argues, with reference to an urban rewilding campaign created to support London becoming a National Park City, that visualisation can be used as part of an agenda to reverse biodiversity loss, and make cities healthier, more sustainable places to live and work. The case study uses architectural drawings of a residential street adapted to enhance its greenspace and biodiversity to encourage residents to transform their homes, gardens and streets. The study found architectural drawings have the potential to inspire and empower people to make changes to their neighbourhood by communicating an aspirational vision, depicting a cohesive proposal at a whole-street scale, and organising practical information and guidance. The case study provides a model for London and other cities to use vision drawings as a catalyst to increase their greenspace and biodiversity, creating a worldwide network of National Park cities.
\end{abstract}

Keywords: Architectural drawing, Biodiversity, City adaptation, Greenspace, Urban rewilding, Visualisation

\section{Introduction}

Background: the value of urban rewilding The problem: loss of urban greenery and biodiversity Globally, urban sprawl is responsible for the loss of greenspace around the city periphery, while densification threatens inner-city greenspaces (Haaland and Konijnendijk van den Bosch 2015). This loss of greenspace makes cities less hospitable to wildlife, which is suffering alarming decline. The UN's Global Assessment Report on Biodiversity and Ecosystem Services concludes that global biodiversity levels on land have dropped by at least $20 \%$ from 1900 and around one million species are at risk of extinction, with changes in land use being the main driver (Díaz et al. 2019). Given this pressure on all land,

*Correspondence: s.moxon@londonmet.ac.uk

The Cass School of Art, Architecture and Design, London Metropolitan University, 16 Goulston Street, London E1 7TP, UK urban wildlife habitat will become increasingly important to mitigate biodiversity decline.

\section{Wider implications: the value of nature for cities and people}

Urban nature benefits cities and their human inhabitants, as well as wildlife, boosting health, wellbeing and the economy.

Residents of urban areas with a higher proportion of green space report better general health (Maas et al. 2006). The benefits of urban greenery stem from the fact that being in a natural environment lowers our blood pressure, pulse rate and stress levels (Park et al. 2010), and makes us feel cognitively and emotionally restored (White et al. 2013). Moreover, the contribution urban green spaces make to our psychological wellbeing has been shown to increase with their biodiversity (Fuller et al. 2007). 
In addition, nature has a monetary value, contributing an estimated \$125 trillion a year to the world economy through ecosystem services (Costanza et al. 2014). These include providing beneficial processes, such as air purification, temperature regulation and flood protection in cities, and the presence of biodiversity has been shown to be important for their effectiveness (Harrison et al. 2014).

As we deprive our urban areas of greenery and wildlife, they therefore function less well and become worse for people. With nearly $70 \%$ of the world's population expected to live in cities by 2050 (UN 2018), the vast majority of us would benefit from them having a greater prevalence of nature.

\section{The solution: rewilding our cities}

We can help reverse these trends of green space and biodiversity loss, by adapting our cities to attract more wildlife, making them healthier and more sustainable places in the process. To this end, principles from the rewilding movement that is restoring lost ecosystems in rural landscapes-of creating spaces for wildlife to re-colonise and enabling people to reconnect with the natural worldcould be applied to cities. Indeed, in cities, dense populations could better facilitate engaging communities in this process.

Restoring greenery would be particularly beneficial in cities, contributing to a functioning 'urban ecosystem'. Firstly, it can mitigate the poor air quality, caused by their high concentrations of traffic and wood-fired appliances, by blocking and dispersing pollutants (Janhall 2015). Secondly, it can address the issues of urban overheating and surface flooding, caused by the ubiquity of hard, dark surfaces in built-up areas, through shading, evapotranspiration and promoting infiltration (Gill et al. 2007; Pauleit and Duhme 2000). These benefits will be increasingly valued as climate change is expected to cause greater incidence of extreme heat and heavy rainfall in many regions (IPCC 2018).

In parallel, cities can make a difference to biodiversity loss. In Britain, built-up areas host twenty percent of the blackbird, starling and song thrush populations and significant numbers of other species (Gregory and Baillie 1998). Species such as peregrine falcons are choosing to become urban specialists, attracted by the nesting-site potential of tall buildings and ready food supply of feral pigeons (Kettel et al. 2019). Further, targeted conservation efforts have prompted increases in urban populations of some bat species (Hayhow et al. 2016).

\section{The target: residential streets}

Loss of greenery from residential areas of cities presents a specific problem, when domestic gardens cover a quarter of major UK cities and contribute a significant proportion of urban vegetation (Loram et al. 2007). Urban gardens, regardless of their small size and remoteness form the countryside, support a huge diversity of wildlife (Smith et al. 2006, 2010; Thompson et al. 2004). In the UK, some species, including the hedgehog, song thrush and common frog, are now more successful in urban gardens than the rural farmland that was once their stronghold (Gregory 1998; Mason 2000).

\section{Aims: engaging residents through drawings Hypothesis: vision drawings}

Visualisation techniques, including freehand sketching and photorealistic computer imaging, have been found to be effective at engaging city residents in planning processes (Al-Kodmany 1999). With this knowledge, the study was developed to explore the hypothesis that architectural drawings combining these representation methods could inspire residents to take an active role in rewilding cities. This was formulated in the research question 'Could architectural drawings be useful in persuading residents to rewild their streets?.

The primary research question generates a series of sub questions, in terms of drawing content, presentation techniques and dissemination:

- What drawing methods would be engaging for residents?

- What positive aspects of urban rewilding should the drawings highlight to residents?

- What barriers to urban rewilding should the drawings seek to dispel among residents?

- How could the drawings relate to practical guidance to form a useful resource?

- How would the drawings reach a public audience?

Architectural drawings have the potential to communicate a vision of a city adapted to enhance its greenspace and biodiversity. Such representation of a biodiverse city could be used to educate and influence inhabitants, designers and policy makers to develop and maintain the city in a way that works towards this vision.

Focusing the vision on existing residential streets would address the significant issue of loss of wildlife habitat in urban gardens. Drawings could inspire and empower residents to make changes to their neighbourhood by showing aspirational ideas, making a cohesive proposal at a whole-street scale, and organising diverse information and guidance.

Appealing images showing how a typical urban residential street could look, after sensitively integrated adaptations, could inspire people to make changes by enabling them to imagine the positive effect on the appearance and experience of their neighbourhood. 
Drawings at the scale of a residential street would show a cohesive proposal, highlighting the potential connectivity of private gardens and critical mass of habitat they can offer when viewed together as a street, if every resident makes even small changes.

Different drawing projections could be used to organise diverse, expert guidance to inform people about potential urban wildlife species and habitats, and empower them to implement biodiversity measures through products or activities.

\section{Literature summary: representation in ecology guidance}

A review was undertaken of the use of drawings and other imagery in UK ecology guidance for residents to determine whether architectural drawings could add anything useful to the field.

The Royal Society for the Protection of Birds (RSPB) and Barratt Homes are collaborating to integrate biodiversity in a new-build housing development on a greenfield site. A combination of annotated drawings and photographs is used to communicate the wildlife features, which include orchards, hedgehog highways, and habitat boxes, to prospective residents (Thomas 2018). The projections used, a site plan and three-dimensional aerial view, are considered successful at showing the proposals at neighbourhood scale, giving the sense of a verdant place with gardens connected to each other and the wider landscape. The aerial view in particular would seem easy for lay people to interpret, and makes good use of people and animals to suggest animation and occupation of the outdoor spaces. However, the illustration style arguably has a simplistic, cartoonish quality: this neither conveys a strong aesthetic design sensibility behind the integration of biodiversity measures nor gives a sense of realism to help people imagine how the development would feel.

Numerous conservation bodies offer advice on wildlife gardening, species and habitats online. The most relevant are RSPB's 'Give Nature a Home', and Royal Horticultural Society (RHS) and the Wildlife Trusts' 'Wild About Gardens' campaigns. These mostly use infographics and photographs in an appealing way. Where used, drawings take the form of scientific illustrations isolated from any context, although the use of hand drawing lends a certain charm. This approach puts the emphasis on adaptations at an individual garden scale, without considering integration with the garden layout or adjoining buildings, or conveying the transformative effect that could be had across streets as a whole. The wealth of expert advice from different organisations can also be hard to navigate, particularly to find information specific to urban species or habitats. Where products to encourage wildlife are recommended, this is done without apparent consideration of their aesthetic merits or compatibility with an urban setting. There is no known design-based advice for the public on sensitively integrating wildlife provision within existing urban streets. There is therefore scope to create guidance that is more persuasive and targeted at city residents by demonstrating considered aesthetic integration of biodiversity measures, showing cumulative impacts at street scale and highlighting an urban application. Drawings were judged to be an effective medium to achieve this, as they enable the designer to invent and control what is shown. Drawing projections and methods were needed that would combine the positive aspects identified above, such as hand drawing and infographics, but give an impression of realism and underlying design thinking. To this end drawing precedents used in design fields were explored.

Books on place-making by Christopher Alexander and on sustainable design by Huw Heywood were consulted for their engaging use of architectural drawings and diagrams to show model designs (Alexander et al. 1977; Heywood 2015). Although intended primarily for a more professional audience, their use of simple, hand-drawn sketches, a variety of drawing projections to capture different ideas and concise annotation to show design principles would be transferable to a lay one. Heywood's use of colour seems especially important to engage a broader demographic. Sarah Wigglesworth Architects' sustainability diagrams for Sandal Magna Primary School in Wakefield were admired for presenting sustainable design concepts in an accessible manner. These concern proposals for primary schools and would therefore be used during the consultation process to engage planners, user and community groups, and the public in proposals. One would assume the use of simple annotated diagrams, hand-drawing, three-dimensional aerial views, colour and leader lines to explain features in more detail contributed to the success of the drawings in convincing these consultees, resulting in the project being built. Finally, the work of certain landscape architects, such as J \& L Gibbons and The Edible Bus Stop, makes good use of image-editing software to show photo-realistic vegetation in proposal drawings used for public consultation. These often show proposals at neighbourhood scale, combining perspectives with more traditional plan and section views. The review determined that a combination of these techniques could be applied to successfully represent urban rewilding in an engaging way.

\section{Why study necessary: creating a drawings-based model}

The study was necessary to find out whether architectural drawings could form the basis of a resource to persuade city residents to make changes to their homes to benefit wildlife. Such a resource could better engage city 
residents and address the gaps identified above in existing urban ecology guidance in the UK, inspiring more urban residents to change their gardens to accommodate greater biodiversity.

Finding a means to engage residents is important, as planning regulations in the UK have negligible scope to control the management of private gardens (Gaston et al. 2005). Policy includes only basic restrictions on impermeable surfacing in front gardens (Communities and Local Government, Environment Agency 2008), unacceptable development in back gardens (Smith 2010) and protected tree removal (Communities and Local Government 2012). Empowered residents might also campaign for their local council to make changes to their streets, and for government and the city mayor to strengthen policy with respect to the existing residential built environment.

The researchers identified an opportunity to reveal original insights through drawings. These comprised creating visually oriented guidance to appeal to lay people appreciating good design; showing a holistic, design-led approach integrating architecture, landscape and urban design; illustrating rural rewilding principles applied to an urban context to allow cities to benefit from species richness; featuring existing, residential streets depicted at a street scale to capitalise on the biodiversity potential of domestic gardens; and collating and organising disparate existing guidance relevant to urban situations.

If effective, this resource would provide a practical, scalable model for effecting change in London and other conurbations. This would help address the wider issue of increasing urbanisation contributing to biodiversity loss worldwide and underpin a future global network of biodiverse National Park cities to counter this trend.

\section{Methods}

\section{The design and drawing process}

The industry-standard design process used by practicing architects in the UK for the early stages of projects was followed to develop the drawings. The drawings were created by a London-based professional team, consisting of an architect-academic, architect and architectural assistant, supported by advice from ecologists. The design oversight of an architect and knowledge of an ecologist were deemed essential to produce drawings showing considered integration of carefully chosen wildlife features into an existing urban street typology. The team used an iterative design process, with sketch drawings used to test ideas, and continuous critical reflection on the research sub-questions regarding the presentation, content and dissemination of the final drawings.

The design team aimed to produce a set of inspirational drawings to communicate a vision of a rewilded city at a street scale, helping residents to imagine the positive impact of adapting their homes for wildlife. To aid implementation of the vision by residents, these drawings would form the basis of a toolkit organising related information and advice.

The precedent study described in the literature summary and Al-Kodmany's findings (1999) were used to identify presentation techniques with the potential to be engaging for residents. Consequently, the drawings were produced as hand-drawn line drawings and rendered in colour using image-editing software to incorporate photo-realistic elements. The aerial view was produced using image-editing software alone, as this projection was deemed easy to read without the need for photo-realism.

The drawings were developed to highlight key positive aspects of urban rewilding that might resonate with inhabitants, identified as increased greenery and colour from vegetation improving street appearance; greater abundance and variety of wildlife; residents, including children and pets, spending more time together outdoors; and community action and cohesion.

Possible barriers to residents carrying out urban rewilding that the drawings should seek to counter were judged to be lack of understanding about why and how to make adaptations for biodiversity; feeling overwhelmed by guidance from different organisations; lack of time or money to implement wildlife measures; concerns over untidiness associated with wildlife gardening or inelegance of wildlife products; fear of attracting unwanted species perceived as invasive, vermin or posing a health and safety risk; lack of space in small urban plots; and occupiers not owning the home.

In line with the findings of the literature review, simple annotation was used to divide the drawings into zones, which related to keys giving further information. Different drawing projections were used to highlight different information, namely species, habitats, products or activities, using links to expert websites to provide further details.

The drawings were collated in an open-access website to enable access by a public audience. This was marketed using social and mainstream media to raise public awareness of the resource. People were encouraged to sign up to the website to receive monthly 'wild makeover' tips and a 'wild makeover guide.'

Evaluation was important to answer the overarching research question, 'Could architectural drawings be useful in persuading residents to rewild their streets?'. This was achieved through internal critical appraisal against the project aims by the design team, alongside external feedback from entering design competitions and awards, monitoring interest on social and mainstream media, and measuring subscribers to the website. 


\section{Siting: London National Park City}

The study was based in London in the UK and the drawings were based on the Victorian (1837-1901) terraced housing typology found throughout the city.

London's status as the world's first National Park City, with a charter committing to making the capital 'greener, healthier and wilder', offered a unique opportunity to test the study's hypothesis. In support of the initiative, the Mayor of London's 'Environment Strategy' report commits to increasing the city's tree cover by $12 \%$ and green space from 47 to $50 \%$ by 2050 , and identifies a need for guidance for residents to protect gardens (Mayor of London 2018).

With almost a quarter of London covered by private gardens (Mayor of London 2018), residential streets are crucial to increasing overall greenspace. Conversely, hard surfacing in the city's gardens increased by $26 \%$ over nine years, representing a substantial loss of vegetation; this has a considerable adverse effect on the biodiversity value of the gardens, especially when considered at a street scale (Smith 2010). There is therefore a need for guidance for homeowners to understand the importance of their gardens to the city's overall greenspace and biodiversity, and to better manage these spaces to enhance their contribution to providing wildlife habitat.

The case study project, 'Rewild My Street', was set up to encourage London's residents to adapt their homes, gardens and streets to augment habitat: reintroducing vegetation and adding features to attract wildlife.

\section{Results}

\section{Drawings and resource}

The case study successfully created a publicly accessible resource centred on architectural vision drawings.

The vision drawings show a snapshot of a notional adapted street through conventional architectural projections, comprising sectional perspective (Fig. 1), plan (Fig. 2), elevation (Figs. 3 and 4) and aerial (Fig. 5) views at a scale of 1:125 at A3. Together, these describe a comprehensive set of proposals for the street.

The drawings are collated on the rewildmystreet.org website. To create a thorough web resource, each vision drawing is employed for a different purpose and has a key cross-referencing the drawing to expert external guidance. The sectional perspective is used to highlight species of wildlife that could be attracted to an urban setting, with links to information on prospective species: categorised by mammal, bird of prey, other bird, amphibian or reptile, invertebrate, and plant or fungus. The street plan in used to show types of natural habitat that could be created in an urban environment-comprising green roof, trees, water, hedgerow, green wall, wildflowers, dead wood, habitat box and wildlife corridor-and has links to information about such habitats. The street and back garden elevations are employed to highlight off-the-shelf products that could be bought to benefit wildlife, and includes links to recommended products. Finally, the aerial view illustrates home-improvement activities that can be carried out to encourage wildlife, and references links to step-by-step guides. Other than the sectional perspective's, the keys are organised by zones that are identified on the drawings and should be recognisable as representing the components of a typical London residential plot. These consist of street, front garden, house, patio, lawn and shed.

The effectiveness of the vision drawings can be analysed by considering their response to each of the research sub questions:

\section{Engaging drawing methods}

The drawings combine many the qualities identified as having potential to be engaging. They feature a range of projections, including three-dimensional views to aid understanding by non-professionals. They combine hand-sketched lines, colour and simple annotation to be appealing and accessible to lay people. Most of the drawings include photo-realistic elements, people and animals to help the public imagine how the place would feel.

The drawings highlight the value of showing the vision at a street scale. The plan and aerial view clearly illustrate the large area of habitat that can be created by connected back and front gardens. The plan, elevations and aerial view show the cumulative greening effect of making changes over the extent of a street. Presenting a whole street enables a single drawing to show a balance between large and small gestures, uniformity and variety. For example, the major intervention of a car-free street park is juxtaposed with more minor changes, such as adding climbing plants. And the homogeneity of the public-private boundary being defined by a continuous hedgerow contrasts with a randomness about which houses have ponds, nesting boxes and green roofs. The drawings should help residents visualise how even small changes they make can contribute to improve their overall street, both aesthetically and experientially.

\section{Showing benefits of rewilding}

The drawings underline the key benefits of urban rewilding identified previously. They showcase an attractive representation of the proposed street, showing trees, hedges, climbing plants, meadows, lawns, pot plants and green roofs for greenery and colour. The drawings show larger animal species, including foxes, squirrels and some birds, to indicate the wealth and diversity of wildlife that could colonise the street. Further, the sectional perspective highlights a broad range of urban species through 


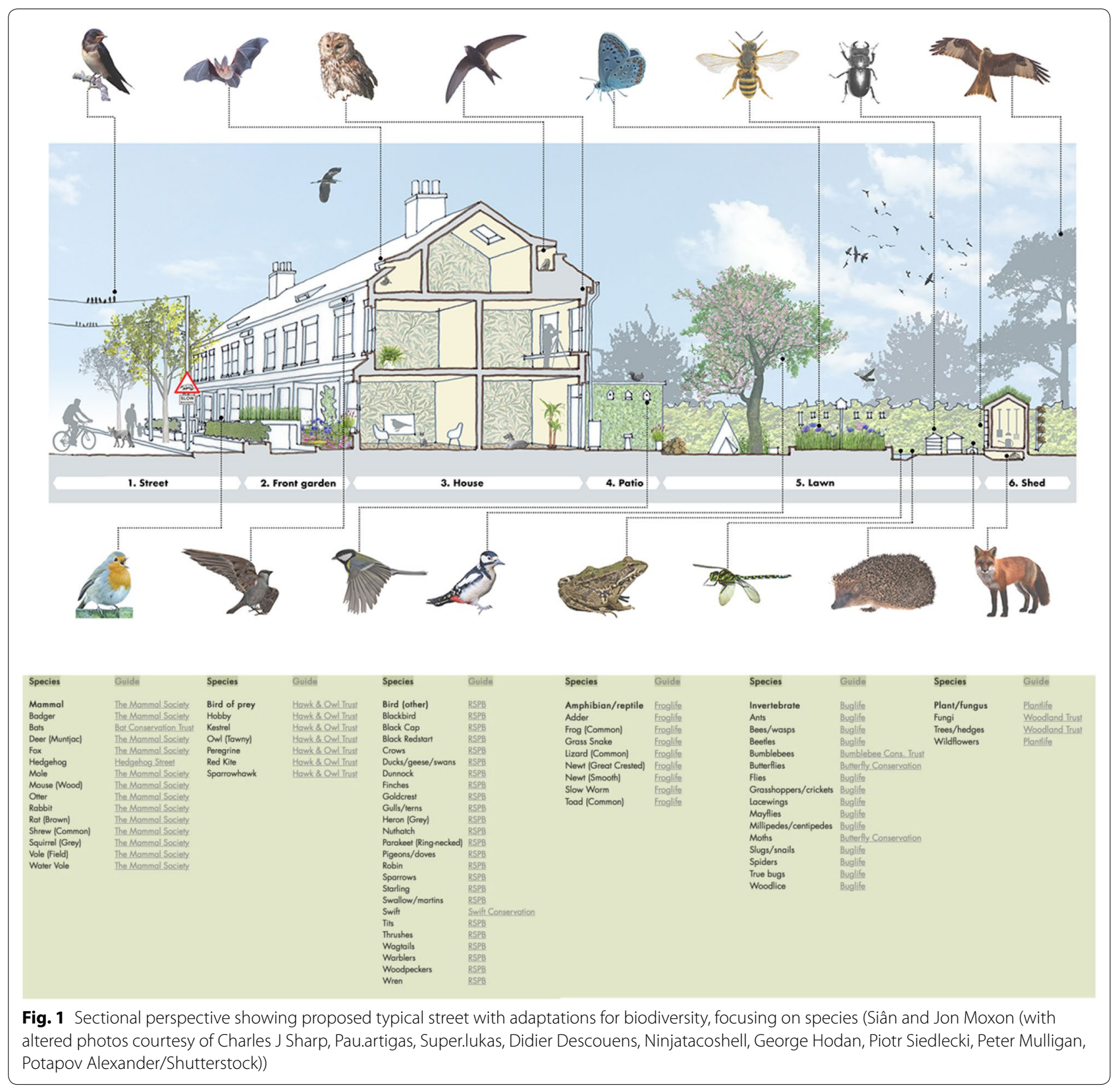

its infographic technique of leader lines pointing to where certain animals might be found. Adults, children and pets are shown enjoying the spaces and their wildlife-through birdwatching, cycling or playing outsideto underline the benefits for people. In particular, the aerial view shows people interacting in the street park and installing wildlife features, such as bird boxes and ponds, in their own gardens, conveying a strong sense of community.

A spatial manifesto is included on the website to explain some of the wider benefits of urban rewilding that would have been difficult to communicate through drawings alone-such as improved air quality, reduced urban overheating and flood risk, and better health and wellbeing-and to underscore the need for community action and working together as a street.

\section{Addressing barriers to rewilding}

The drawings address the aforementioned obstacles to urban rewilding residents might experience. Showing the proposals at street scale allows people to see how individual actions in their own garden can combine with those 

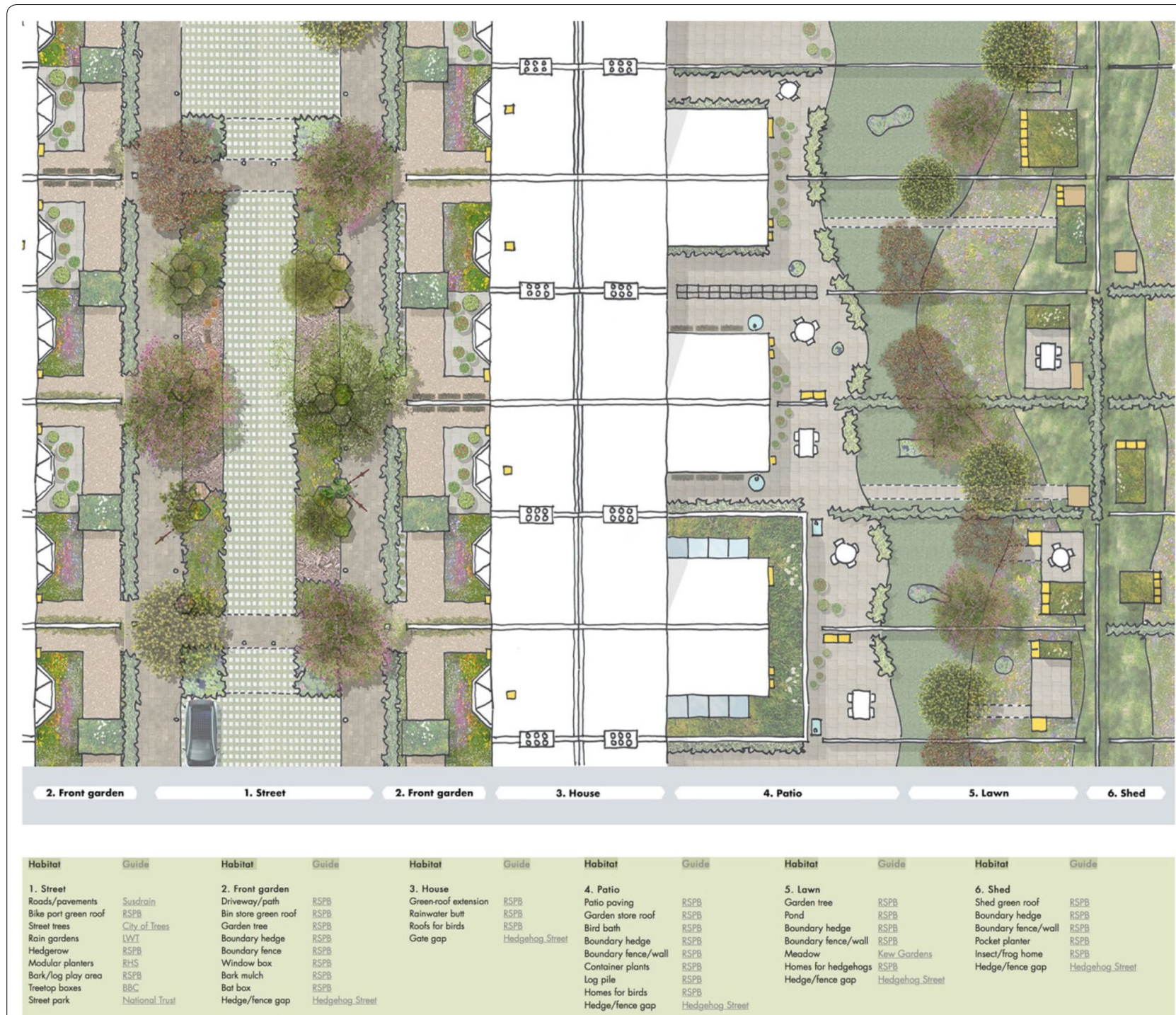

Fig. 2 Street plan showing proposed typical street with adaptations for biodiversity, focusing on habitat (Siân \& Jon Moxon \& Viktoria Fenyes)

of their neighbours to contribute to a much larger habitat. The use of keys accompanying the drawings relates the visuals to educational information on the importance of encouraging key species and habitats in gardens, and how to do so, via web links. The keys thus collate guidance from diverse organisations, limiting content to that suitable for urban settings, for instance species that can thrive in city gardens and products with a contemporary style, making it easier for residents to navigate. To give residents choices for implementation to suit their priorities, quicker off-the-shelf and cheaper do-it-yourself options are given for each adaptation, on the products and activities keys, respectively: for example, to create a mini pond one can buy a patio pond, consisting of a ceramic bowl complete with native aquatic plants, or follow a step-by-step guide to make your own from a found container. Presenting the adaptations as a list and showing the street as a whole also makes it clear that each resident could do one, a few or all things, depending on their circumstances, to make a cumulative difference.

The vegetation is deliberately drawn neatly to show that wildlife gardening can be orderly. Clean lines and upstands indicate clipped edges or defined edging to contrast with and contain the more informal outlines of meadow planting, trees and hedges. Moreover, the wildlife features are illustrated as integrated into the existing urban setting to optimise appearance: for example, bat tiles are shown discreetly within the 

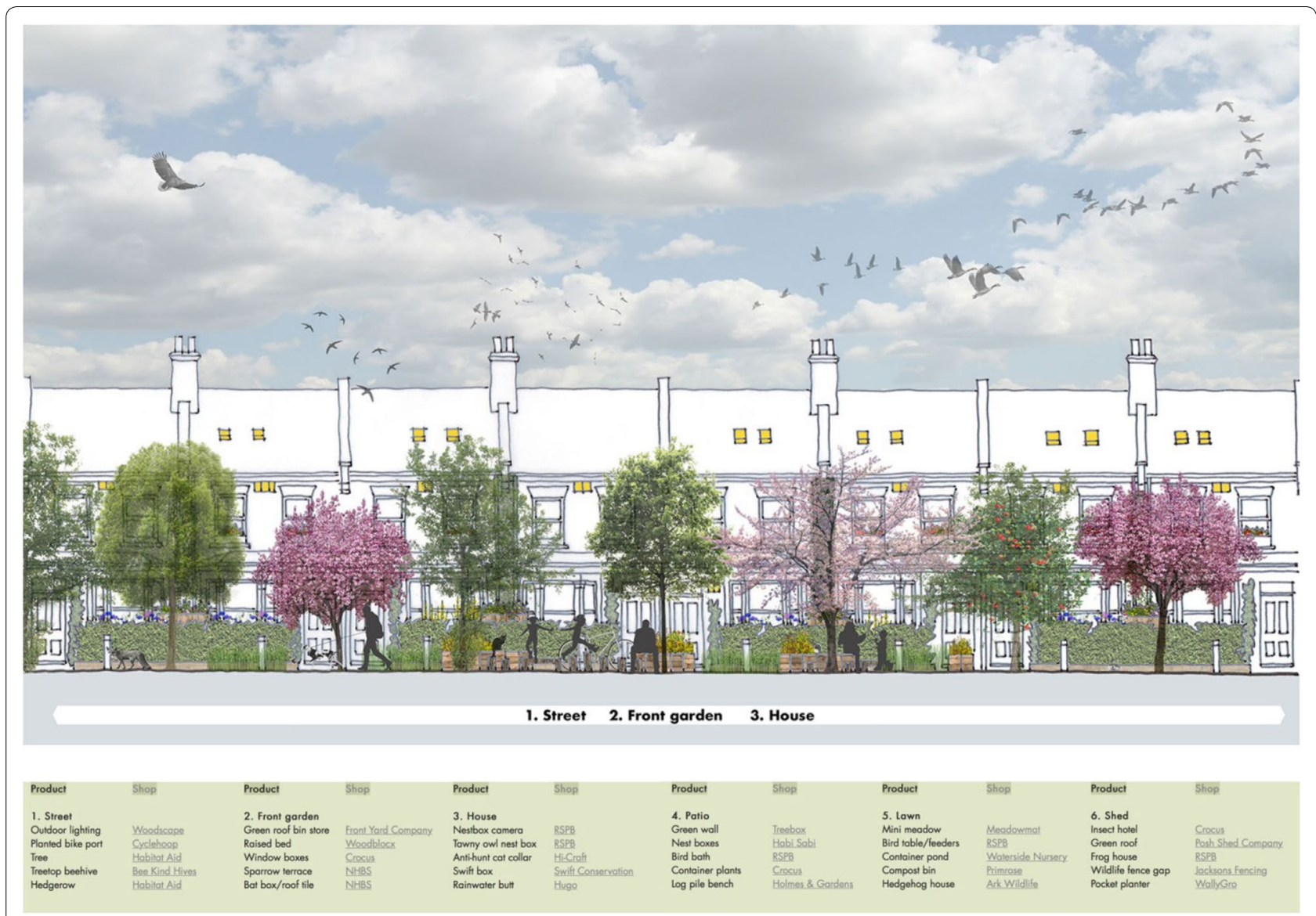

Fig. 3 Street elevation showing proposed typical street with adaptations for biodiversity, focusing on products (Siân \& Jon Moxon \& Viktoria Fenyes)

pitched roofs; and habitat boxes, bird feeders and compost bins are drawn as simple, geometric shapes to suit the orthogonal nature of the built-up environment.

The drawings seek to show a wide range of animals to reassure people that, in a rewilded environment, species that might polarise opinion, such as foxes, would be better balanced by more universally popular species like robins and hedgehogs. Nevertheless, obviously contentious species, including verminous rats and nonnative parakeets, are avoided.

The drawings show that a host of wildlife habitats could be incorporated in a small plot. Space is optimised by applying adaptations to existing horizontal and vertical surfaces, through green roofs and walls, wall-mounted habitat boxes and bird feeders; or showing small versions of habitats, such as mini meadows or container ponds. For those renting their homes, unfixed and portable features, for instance pocket fence planters and window boxes, should not require permission from the landlord and could be taken to another property. Besides, the street-scale drawings convey that anything more permanent could be left as a legacy to benefit the overall neighbourhood.

\section{Organising guidance}

Annotating the drawings with keys enables a vast amount of guidance from different sources to be organised in a logical, coherent manner. Allocating each drawing a different purpose and associating it with a related key helps residents quickly access the information they want. Dividing the drawings into zones allows the guidance to be broken down further to relate to where they are located on the drawings: for instance, to find products one might install in the front garden. Presenting the drawings on a website allows this guidance to be collated in one place, making use of interactive links to external expert sources. The consistency between the drawings, in terms of presentation style and content retains a sense of harmony across the distinct areas of guidance. 


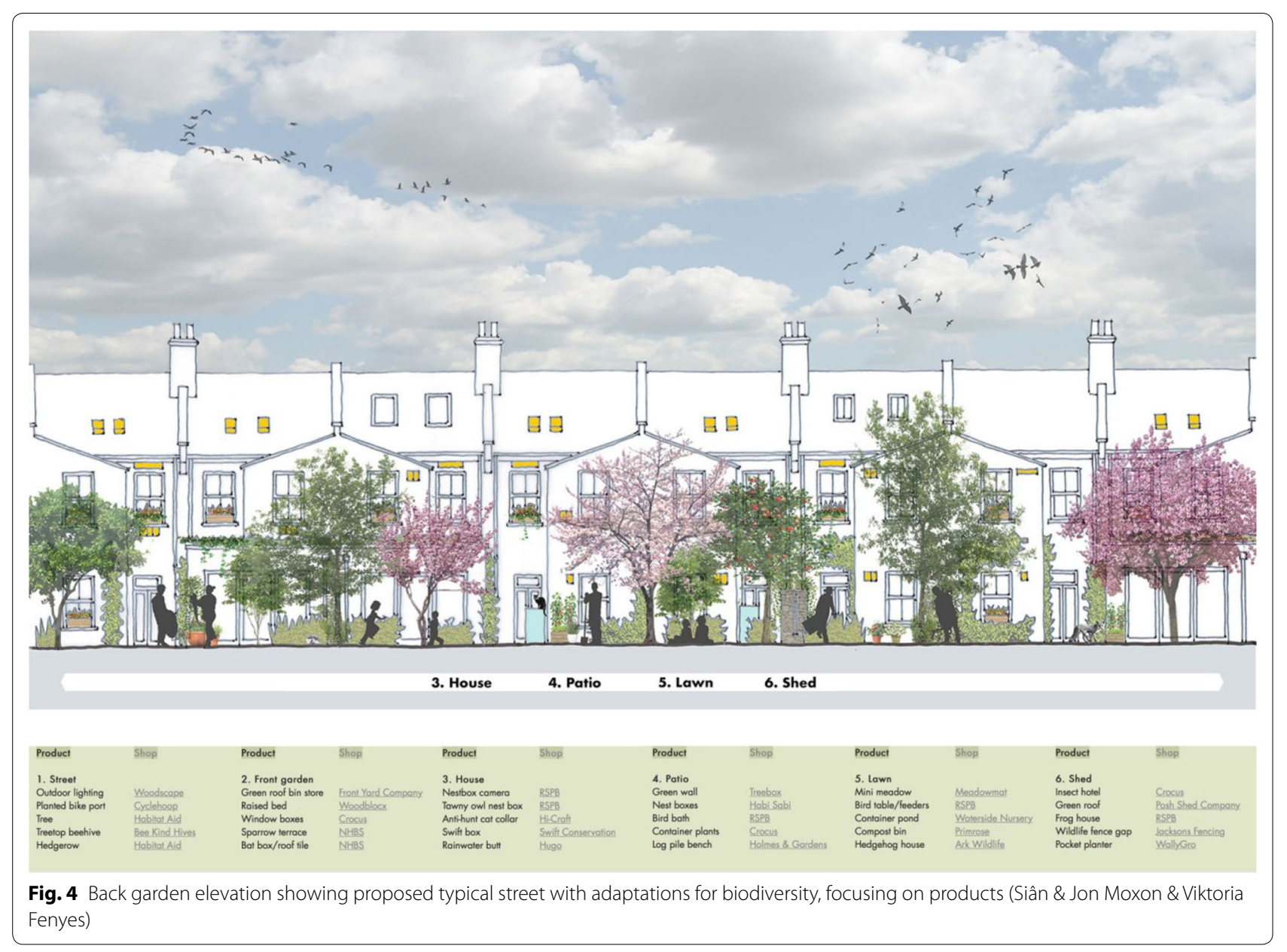

\section{Reaching a public audience}

The website is open-access and its resources can be used without registering to ensure the drawings are accessible to a public audience. Publicity on social and mainstream media, and via competition entries and events is used to raise awareness of the project among residents and encourage use of the website. Alliance with key organisations, such as the National Park City Foundation and Wildlife Gardening Forum, has also helped to promote the website to its target audience.

\section{Promoting urban rewilding through architectural drawings} We can now consider the outcome in relation to the primary research question 'Could architectural drawings be useful in persuading residents to rewild their streets?.' Given that the critical review of the case study has shown that architectural drawings can be engaging, can highlight positive aspects and dispel negative aspects of urban rewilding, can effectively organise guidance and can be made accessible to a public audience, the answer appears to be affirmative. The completed visuals and web resource effectively communicate the concept of a rewilded city through architectural drawings that have visual appeal and enable sensitive integration of adaptations for biodiversity into an existing Victorian street typology.

Vitally, this outcome is echoed by external feedback from public, professional and academic audiences. The drawings were instrumental in the project being recognised by the judging panels of the Imagine London as a National Park City international design-ideas competition, which the project won; and London Metropolitan University's Big Idea Challenge and London Sustainability Exchange's Sustainable City Awards, for which it was a finalist. A new drawing of a rewilded balcony was commissioned for the London National Park City launch magazine: the drawing was previewed on social media, attracting 220 'likes' and many favourable comments on its appearance and usefulness from London residents and local organisations, such as 'Love this. Very achievable' and 'This looks amazing'. A survey by Imperial College London students based on the project found that $87 \%$ of 


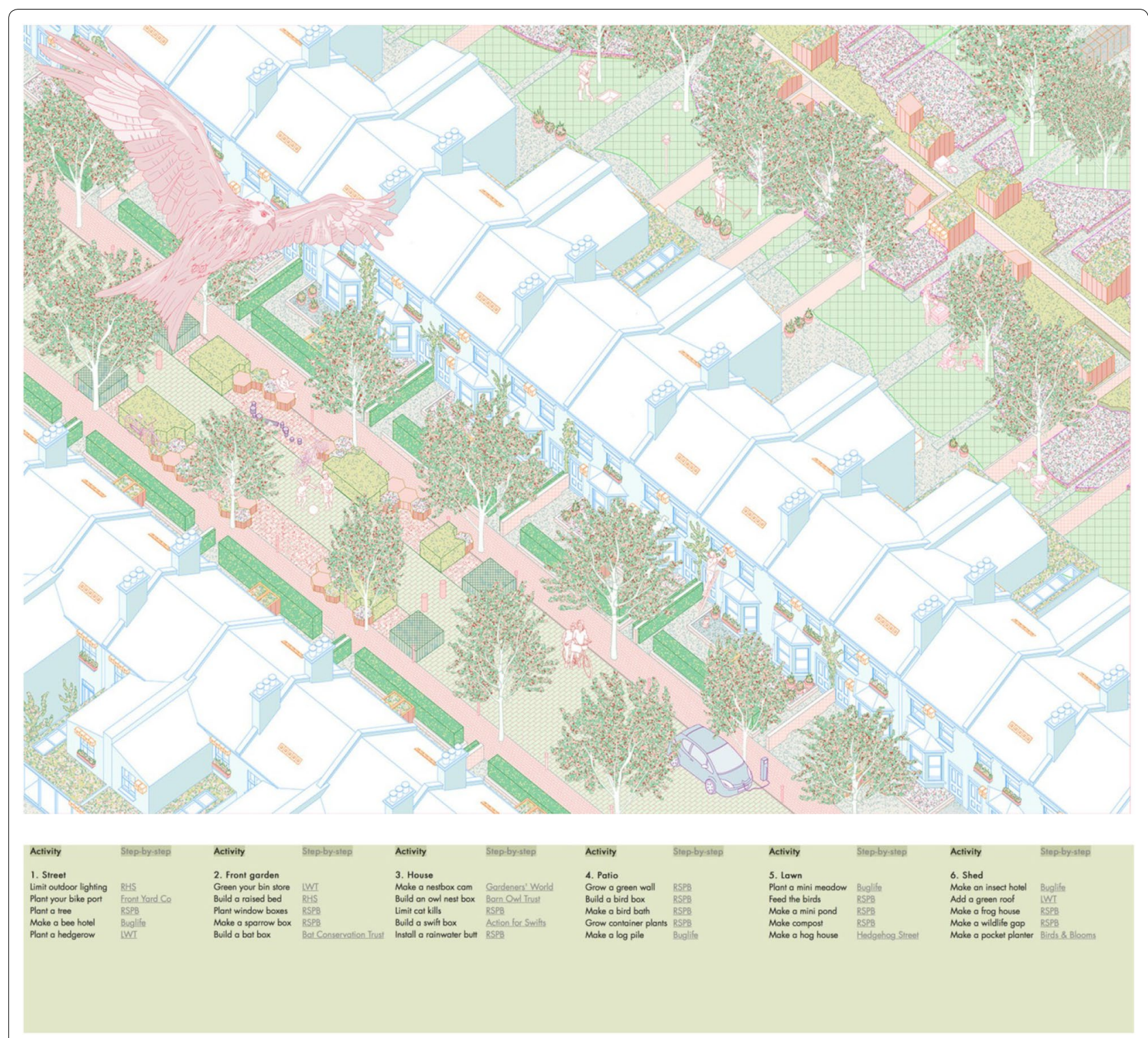

Fig. 5 Aerial view showing proposed typical street with adaptations for biodiversity, focusing on activities (Viktoria Fenyes)

500 respondents from across Greater London supported implementing the proposals shown on the drawings.

In addition, the drawings have been selected for display in the Design Research for Change exhibition, as part of London Design Fair. Imagery from the project is continuing to help attract mainstream media coverage, 650 social media followers, 90 mailing list subscribers and endorsement by related organizations. The drawings have been published by the UK's leading architectural trade journal, conservation organisations, and several influential London lifestyle magazines; and presented at the UK's foremost sustainability trade show. Publicity and monitoring of uptake is ongoing, but this initial reaction signifies that visionary architectural drawings can engage people and inspire them to improve their urban environment.

\section{Discussion}

The study confirms that architectural drawings can be used to promote the ideal of a biodiverse city and can underpin resources to achieve this ideal. It makes a timely contribution to the field of design research, capturing current high public awareness of environmental issues, including biodiversity loss. It makes a novel contribution to ecology by focusing on urban rewilding; tackling existing residential contexts; thinking at street scale; and using design drawings as a catalyst for nature 
conservation. The resulting output fills a gap in existing resources by providing practical, visual guidance for lay people that is specific to urban contexts.

The project outputs form a useful model for encouraging sustainable urban redevelopment through designled, street-scale, visually oriented guidance. This model should now be built upon by the study team and, indeed, offers opportunities for other researchers to expand the study globally.

For Rewild My Street, the project resources can be expanded and their effectiveness measured. The resources would benefit from the addition of an animation to compliment the static drawings, showing the gradual rewilding of a street over time and giving a sense of interest over the seasons. This could use the same style of coloured hand-drawing to be engaging, but would enable the communication of more complex ecological processes and interactions.

As the project is at an early stage, it will be important to continue to generate and analyse empirical data to objectively measure both the public response to the drawings and the impact on biodiversity of following the recommendations depicted. Wider marketing should take place before an accurate assessment can be made of the initiative's popularity. This should target policy makers and designers, as well as residents, to facilitate implementation in the streetscape and on larger-scale retrofit projects. Website users and social media followers should be formally surveyed to establish the effectiveness of the drawings at inspiring them to make changes and informing them of how to do so.

Thinking more broadly, the principle of using vision drawings to drive sustainable redevelopment of cities can be applied elsewhere. Similar vision drawings could be produced of streets with alternative residential typologies, for example blocks of high-rise flats with communal gardens or suburban detached or semi-detached homes, to show how the principles would look when applied to different urban environments. These could represent street typologies prevalent in other towns and cities, in the UK or in other countries and climates. The approach could be extended to show adaptations to other existing buildings types, such as schools, shops or offices, as well as prototype new-build proposals. The same research questions could be applied to decide the drawings' appearance and content. The principles of what makes an engaging drawing might conceivably vary between different audiences and cultures. The drawings could organise guidance under the same categories, although the content would differ to suit the building type, and local species and habitats. The method of dissemination might also differ for some building user groups, perhaps using relevant industry forums. The positive and negative associations of rewilding would also need to be re-assessed for the target demographic and location, as these are perhaps driven by socio-economic and cultural factors.

The study could inspire other projects using vision drawings to prompt sustainable redevelopment of cities. These could highlight other important environmental concerns, such as air pollution, rainwater management or urban farming, that would contribute to a general aim of reimagining our cities as greener places for future resilience. The principles of what makes an engaging drawing, how to organise guidance and how to make a public resource are likely to be transferable, while similar research questions could be interrogated to identify how to address benefits and barriers to the initiative in question through the drawings.

\section{Conclusions}

In summary, city representation has a critical role in addressing pressing environmental problems by engaging people to change their environment.

Architectural drawings offer a powerful tool to convince the public of the value of rewilding their streets, generate publicity for environmental campaigns, encapsulate considered design ideas and organise practical guidance. Hence, architectural drawings can be a catalyst for the transformation of conurbations into green havens for biodiversity.

There is an urgent need to persuade city residents to re-provide urban greenery to address the global trends of urban greenspace and biodiversity loss. Existing domestic gardens have great potential to provide significant additional greenspace and habitat for wildlife, and principles of rewilding can be applied to city streets to achieve this. Residents are best placed to effect change, and guidance is needed to inspire and enable them to make positive interventions to enhance their spaces. In so doing we will capitalise on the many benefits of urban nature for people, and transform towards sustainable cities that are better places to live and resilient to future climate change.

The case study project has successfully created a resource founded on architectural drawings to foster urban rewilding in support London's aspirations as a National Park City. There is now scope to apply this model to other urban contexts and building typologies, so that other projects can make similar use of city representation to drive environmental change. This could help address the global challenges of growing urbanisation and environmental damage, including biodiversity loss, and see the creation of a growing network of National Park cities demonstrating greater harmony between the built environment and nature. 


\section{Abbreviations}

UK: United Kingdom; UN: United Nations.

\section{Acknowledgements}

Jon Moxon of MXN Architecture, and Stacey Cougill and Rachel Crookes of Eight Associates ecologists have an advisory role on the project.

\section{Authors' contributions}

The author read and approved the final manuscript.

\section{Authors' information}

Siân Moxon (BSc BArch ARB BREEAM-AP FHEA) is a Senior Lecturer in sustainable design and researcher in urban biodiversity at London Metropolitan University. She is an architect, BREEAM accredited professional and the author of 'Sustainability in Interior Design'. She is the founder of the Rewild My Street urban rewilding campaign.

\section{Funding}

The study was funded by London Metropolitan University.

\section{Availability of data and materials}

The online resource is available at https://www.rewildmystreet.org.

\section{Competing interests}

The author declares no competing interests.

Received: 2 March 2019 Accepted: 6 September 2019 Published online: 23 September 2019

\section{References}

Alexander C, Ishikawa S, Silverstein M, Jacobson M, Fiksdahl-King I, Shlomo A (1977) A pattern language: towns, buildings, construction. Oxford University Press, New York

Al-Kodmany K (1999) Using visualization techniques for enhancing public participation in planning and design: process, implementation, and evaluation. Landsc Urban Plan 45(1):37-45. https://doi.org/10.1016/ S0169-2046(99)00024-9

Communities and Local Government (2012) Protected trees: a guide to tree preservation procedures. Communities and Local Government Publications. https://assets.publishing.service.gov.uk/government/uploads/ system/uploads/attachment_data/file/244528/2127793.pdf. Accessed 1 Mar 2019

Communities and Local Government, Environment Agency (2008) Guidance on the permeable surfacing of front gardens. Communities and Local Government Publications. https://assets.publishing.service.gov. uk/government/uploads/system/uploads/attachment_data/file/7728/ pavingfrontgardens.pdf. Accessed 1 Mar 2019

Costanza R, de Groot R, Sutton P, van der Ploeg S, Anderson SJ, IKubiszewski I, Farber SR, Turner K (2014) Changes in the global value of ecosystem services. Global Environmental Change 26:152-158. https://doi. org/10.1016/j.gloenvcha.2014.04.002

Díaz S, Settele J, Brondizio ES, Ngo HT, Guèze M, Agard J, Arneth A, Balvanera P, Brauman K A, Butchart SHM, Chan KMA, Garibaldi LA, Ichii K, Liu J, Subramanian SM, Midgley GF, Miloslavich P, Molnár Z, Obura D, Pfaff A, Polasky S, Purvis A, Razzaque J, Reyers B, Roy Chowdhury R, Shin YJ, Visseren-Hamakers IJ, Willis KJ, Zayas CN (eds) IPBES (2019) Global assessment report on biodiversity and ecosystem services of the Intergovernmental Science-Policy Platform on Biodiversity and Ecosystem Services. IPBES secretariat, Bonn, Germany. https://www.ipbes.net/ global-assessment-report-biodiversity-ecosystem-services

Fuller RA, Irvine KN, Devine-Wright P, Warren PH, Gaston KJ (2007) Psychological benefits of greenspace increase with biodiversity. Biol Lett. https://doi.org/10.1098/rsbl.2007.0149

Gaston KJ, Smith RM, Thompson K, Warren PH (2005) Urban domestic gardens (II): experimental tests of methods for increasing biodiversity. Biodivers Conserv 14:395-413. https://doi.org/10.1007/s10531-004-6066-x

Gill SE, Handley JF, Ennos AR, Pauleit S (2007) Adapting cities for climate change: the role of green infrastructure. Built Environ 33(1):115-133. https://doi.org/10.2148/benv.33.1.115
Gregory RD, Baillie SR (1998) Large-scale habitat use of some declining British birds. J Appl Ecol 35(5):785-799. https://doi.org/10.104 6/j.1365-2664.1998.355349.x

Haaland C, Konijnendijk van den Bosch C (2015) Challenges and strategies for urban green-space planning in cities undergoing densification: a review. Urban For Urban Green 14(4):760-771. https://doi. org/10.1016/j.ufug.2015.07.009

Harrison PA, Berry PM, Simpson G, Haslett JR, Blicharska M, Bucur M, Dunford R, Egoh B, Garcia-Llorente M, Geamănă N, Geertsema W, Lommelen E, Meiresonne L, Turkelboom F (2014) Linkages between biodiversity attributes and ecosystem services: a systematic review. Ecosyst Serv. 9:191-203. https://doi.org/10.1016/j.ecoser.2014.05.006

Hayhow DB, Burns F, Eaton MA, Al Fulaij N, August TA, Babey L, Bacon L, Bingham C, Boswell J, Boughey KL, Brereton T, Brookman E, Brooks DR, Bullock DJ, Burke O, Collis M, Corbet L, Cornish N, De Massimi S, Densham J, Dunn E, Elliott S, Gent T, Godber J, Hamilton S, Havery S, Hawkins S, Henney J, Holmes K, Hutchinson N, Isaac NJB, Johns D, Macadam CR, Mathews F, Nicolet P, Noble DG, Outhwaite CL, Powney GD, Richardson P, Roy DB, Sims D, Smart S, Stevenson K, Stroud RA, Walker KJ, Webb JR, Webb TJ, Wynde R and Gregory RD (2016) State of Nature 2016. The State of Nature partnership. https://www.rspb.org.uk/globa lassets/downloads/documents/conservation-projects/state-of-nature/ state-of-nature-uk-report-2016.pdf

Heywood H (2015) 101 rules of thumb for sustainable buildings and cities. RIBA Publishing, London

IPCC (2018) Special report: global warming of $1.5^{\circ} \mathrm{C}$ : summary for policymakers. World Meteorological Organization, Geneva. https://www.ipcc. ch/sr15/chapter/summary-for-policy-makers/. Accessed 1 Mar 2019

Janhall S (2015) Review on urban vegetation and particle air pollutiondeposition and dispersion. Atmos Environ 105:130-137. https://doi. org/10.1016/j.atmosenv.2015.01.052

Kettel EF, Gentle LK, Yarnell RW, Quinn JL (2019) Breeding performance of an apex predator, the peregrine falcon, across urban and rural landscapes. Urban Ecosyst 22(1):117-125. https://doi.org/10.1007/s1125 2-018-0799-x

Loram A, Tratalos J, Warren PH, Gaston KJ (2007) Urban domestic gardens $(X)$ : the extent and structure of the resource in five major cities. Landsc Ecol 22(4):601-615. https://doi.org/10.1007/s10980-006-9051-9

Maas J, Verheij RA, Groenewegen PP, de Vries S, Spreeuwenberg P (2006) Greenspace, urbanity and health: how strong is the relation? J Epidemiol Community Health 60(7):587-592. https://doi.org/10.1136/ jech.2005.043125

Mason CF (2000) Thrushes now largely restricted to the built environment in eastern England. Divers Distrib 6(4):189-194. https://doi.org/10.104 6/j.1472-4642.2000.00084.x

Mayor of London (2018) London environment strategy. Greater London Authority. https://www.london.gov.uk/sites/default/files/london_envir onment_strategy.pdf. Accessed 1 Mar 2019

Park BJ, Tsunetsugu Y, Kasetani T, Kagawa T, Miyazaki Y (2010) The physiological effects of Shinrin-yoku (taking in the forest atmosphere or forest bathing): evidence from field experiments in 24 forests across Japan. Environ Health Prev Med 15(1):18-26. https://doi.org/10.1007/ s12199-009-0086-9

Pauleit S, Duhme F (2000) Assessing the environmental performance of land cover types for urban planning. Landsc Urban Plan 52(1):1-20. https:// doi.org/10.1016/S0169-2046(00)00109-2

Smith C (2010) London: garden city?: investigating the changing anatomy of London's private gardens, and the scale of their loss. London Wildlife Trust, Greenspace Information Greater London, Greater London Authority. https://www.gigl.org.uk/partnershipcasestudy/garden-resea rch/. Accessed 31 July 2019

Smith RM, Thompson K, Hodgson JG, Warren PH, Gaston KJ (2006) Urban domestic gardens (IX): composition and richness of the vascular plant flora, and implications for native biodiversity. Biol Conserv 129(3):312322. https://doi.org/10.1016/j.biocon.2005.10.045

Smith RM, Thompson K, Warren PH, Gaston KJ (2010) Urban domestic gardens (XIII): composition of the bryophyte and lichen floras, and determinants of species richness. Biol Conserv 143(4):873-882. https:// doi.org/10.1016/j.biocon.2009.12.033

Thomas A (2018) Neighbourhoods for Nature. Nature's Home. Summer:28-34. https://www.rspb.org.uk/globalassets/downloads/docum 
ents/conservation-projects/nature-home-kingsbrook.pdf. Accessed 31 July 2019

Thompson K, Hodgson JG, Smith RM, Warren PH, Gaston KJ (2004) Urban domestic gardens (III): composition and diversity of lawn floras. J Veg Sci 15(2):373-378. https://doi.org/10.1007/s10980-004-3160-0

United Nations (2018) World urbanization prospects: the 2018 revision. https://population.un.org/wup/Publications/Files/WUP2018-KeyFacts. pdf. Accessed 31 July 2019
White MP, Phal S, Ashbullby K, Herbert S, Depledge MH (2013) Feelings of restoration from recent nature visits. J Environ Psychol 35:40-51. https:// doi.org/10.1016/j.jenvp.2013.04.002

\section{Publisher's Note}

Springer Nature remains neutral with regard to jurisdictional claims in published maps and institutional affiliations.
Submit your manuscript to a SpringerOpen ${ }^{\circ}$ journal and benefit from:

- Convenient online submission

- Rigorous peer review

- Open access: articles freely available online

- High visibility within the field

- Retaining the copyright to your article

Submit your next manuscript at $\boldsymbol{\nabla}$ springeropen.com 